\title{
Designing and embedding authentic learning opportunities in a social work curriculum: Reflections and lessons learned
}

\author{
Eva Bowers ${ }^{1}$, Margaret Pack ${ }^{2}$
}

\begin{abstract}
INTRODUCTION: A challenge for many busy educators in social work is how to design realistic case studies to evoke learning experiences that engage the imagination and clinical reasoning of the student. This article focuses on the authors' experiences of designing and developing authentic case scenarios to embed in learning in a four-year Bachelor of Social Work programme in Australia.
\end{abstract}

METHOD: Assisted by a grant from the Australian Government Office of Learning and Teaching, a project plan was developed, inspired by Lipsky's (2010) framework, "street level bureaucracy" and methodology derived from Maynard-Moody and Musheno (2012). The aim was to produce a series of online, filmed podcasts to be embedded into blended learning to enable students to build confidence in ethical decision making.

FINDINGS: Early results from the project suggest that the students found deliberating on ethical dilemmas evoked by the resource a useful addition to more conventional teaching approaches as it tangibly demonstrated the connection of theory to practice in action.

IMPLICATIONS: The approach to both conceptualising and developing such resources could further be utilised in social work education settings and more broadly, in human services occupations including the health sector to focus on confidence building in ethical decision making and navigating the complex interplay between theory and practice. There is potential for the approach to be adapted and used as a reflective tool for established social workers.

KEYWORDS: child protection, social work education, ethical decision making, supervision, online education

Two important pedagogical principles predominate in the learning method of supervised practice for social work students explored in this article-active learning and authentic learning (Bloomfield, Chambers, Egan, \& Goulding, 2013). These principles are embedded in an apprenticeship model by which the student learns from academic teachers and practitioners acting as fieldwork supervisors who, through their interaction with the learner, stimulate a critical reflective process. It is through this critical reflective process that the beginning practitioner, upon graduation and entry to practice, learns how to effectively interact interpersonally within the workplace and to navigate complex systems (MacDonald, 2002). Authentic learning relates to the ways in which educators and social work practitioners enact intellectual understandings and translate these into action through their practice (Bloomfield et al., 2013). Most often, a case
${ }^{1}$ Northern Sydney Institute, TAFE NSW, Australia

${ }^{2}$ Consultant, Aotearoa New Zealand
AOTEAROA

NEW ZEALAND SOCIAL WORK 29(1), 99-110.

CORRESPONDENCE TO: Margaret Pack marg@margaretpack.nz 
study approach is used to evoke complex practice themes and ethical dilemmas through which beginning practitioners can creatively take the role of the social worker in the situation and context under study and consider an appropriate course of action amongst a range of alternatives.

The use of case studies has gained growing recognition in teacher education as a tool that is based in principles of authentic assessment. Darling-Hammond and Synder (2000, p. 529) identify four tools that reflect principles of authentic assessment: case studies, portfolios, exhibitions of performance and problem-based inquiry. Case studies are identified as an effective tool in social work teaching and learning because they add context to theory; making theory more "real" for students. Furthermore, case studies encourage student thinking in response to practice dilemmas. Critical reflection and application of knowledge engages students to see and imagine possibilities (Schulman, cited in Darling-Hammond \& Synder, 2000, p. 530).

Case studies, to be aligned with realities of practice, need to draw on multiple sources of evidence collected over time and in diverse, complex and culturally sensitive contexts (Darling-Hammond \& Snyder, 2000). Assessment of what to include in case studies is, ideally, guided by the practitioners themselves. Such case studies facilitate multiple opportunities for learning and rehearsing frequently encountered practice scenarios. Lastly, authentic assessment should ideally include learners' feedback and reflection as part of the wider learning process.

Lipsky's (2010) now classic theorising about the use of discretion by human service workers is relevant and, we argue, central to the development of authentic case studies. Lipsky (2010), through his research with human service workers, lays bare the ambiguous role social workers and other human service professionals face on a dayto-day basis. As street-level bureaucrats, they are typically:
... the focus of citizen reactions because their discretion opens up the possibility that they will respond favourably on behalf of that the individual. Their general and diffuse obligation to the "public interest" permits hope to flourish that the individual worker will adopt a benign or favourable orientation towards the client. Thus, in a world of large and impersonal agencies that apparently hold the keys to important benefits, sanctions, and opportunities, the ambiguity of work definitions sustains hope for a friend in court. (pp. 9-10)

Maynard-Moody and Musheno (2003) draw from Lipsky's work to assemble narratives illustrating how social workers, teachers, and other helping professionals balance the departmental policy imperatives with the perception that they can broker goods and services on behalf of clients. In doing this, they highlight, through themes derived from interviews with a range of helping professionals, how workers make complex decisions within these competing expectations and job requirements to produce an ethical course of action. It was our hope to gather similar narratives of practice to teach students about complex decision making in child protection social work and, in particular, to demonstrate the use of discretion in this field of practice.

\section{Project aims}

The primary aim of the project was to develop, implement and evaluate a new digital resource to enable undergraduate social work students to understand, explore and practise the difficult work of discretion in everyday professional life in human services. As educators, we placed emphasis on child protection social work due to local workforce development priorities in the region in which we were working: the Northern Territory of Australia. Within this aim the principles that guided the project team were drawn from the concept of authentic assessment (Darling-Hammond \& Snyder, 2000). Authentic assessment includes four 
main principles guiding the development of higher degree programmes. These principles are summarised by Darling-Hammond and Synder (2000), citing the foundational work of Reinman, which refers to the integration of multiple forms of knowledge and skill as they are used in practice. These principles are that case studies are designed to contextualise theory and the field of practice, thus encouraging students to imagine themselves in that situation and to engage with practice dilemmas through a process of critical reflection. Through this process, experiential and theoretical knowledge is applied to the case, thus bridging the gap between personal/life knowledge and professional knowledge involving more abstract concepts and sources (Darling-Hammond \& Synder, 2000, p. 530).

\section{Literature review}

As a preliminary step to undertaking the evaluation and composing the grant application, a review of previous research on case study development in social work was undertaken. This research process highlighted the significance of critical reflection and how this is taught both in higher education and in practice settings. A critical reflective approach work has been of importance historically in social work teaching (Mezirow, 1990; Schön, 1987). Critical reflection can support professional development through examining decisions and actions. Articulation of this reflection can feed back into policy and practice and lead to improvements in service delivery for clients and their families. (Gambrill, 2006). Critical reflection in social work practice and education has a role in raising awareness of the effective "use of self", supporting the emergence of a coherent professional identity; ultimately promoting the ability to analyse power which leads to new knowledge building. Critical reflective capabilities cannot be fully explored without experiencing the process of practice dilemmas and the impact on the work of the practitioner (Napier \& Fook, 2000). Critical reflection may not be an intuitive skill and teaching and learning environments can assist in developing comprehensive approaches to building reflective capabilities (Ryan, 2013). This is particularly important in social work education as we want to equip graduates with the skills and knowledge to apply critical reflective capabilities in a complex work environment. In embedding the use of web-based resources there is an opportunity to use and create educational resources that prepare students for the practical realities of social work and expose students in a safe, facilitated way to some of the dilemmas that lie ahead of them, in particular, the use of discretion.

As social workers, we also wished to model the cultural and organisational environments within which social workers operate, mirroring Lipsky (2010) and Maynard-Moody and Musheno's (2003) work. As the second author was originally from Aotearoa New Zealand and had dual membership of both Australian Association of Social Workers (AASW) and Aotearoa New Zealand Association of Social Workers (ANZASW), she wished the case studies to highlight examples of "decolonising methodologies" (Smith, 1999). Smith writes of research as a Eurocentric construct, to be viewed as a colonising practice. Thus, the case studies were intended to raise examples which students were asked to deconstruct in the way that researchers are asked by Smith (1999) to deconstruct their own practices as researchers. Within this decolonising approach researchers are asked to be mindful of the way in which their power positioning imposes an order on those researched (Smith, 1999). Similarly, students are asked about the power differences between the Department of Children and Families social workers depicted in the case studies and their use of intervention with their clients. This analysis of power and powerlessness formed an integral part of each case study. For example, although government department policies might aim at working to address institutional racism and inequality, the actions taken by social workers to operationalise policy and to translate manual 
directives into practice might inadvertently reflect institutional racism through the ways in which the broad systems operate to unintentionally exclude (or negatively discriminate against) individuals or groups in society. The unconscious nature of what we do as social workers when we are asked to follow policy directives uncritically while under pressure, facilitates the operation of institutional racism in the organisational context. Decolonising practices (Smith, 1999) became an important learning focus for students when observing what the social workers in the scenarios did in practice. For example, depicting a white, Australian, male social worker working in a remote Aboriginal community has many challenges. How to reveal the internal struggle he faces in working outside his cultural comfort zone, illustrated by his moral and ethical reasoning in the case, was a unique feature of each case scenario. Our aim was to be transparent about his attitudes, worldview and beliefs as he grappled with the ambiguity of how to do his job, in light of the fact that he did not share the same cultural background and understandings of many of his clients.

\section{Methodology}

A project team was appointed when the \$50,000 Federal Government Office of Learning and Teaching Innovation grant was awarded to the university following the successful grant application by the project team. The team included social work advisors from the Department of Children and Families in Darwin, a project officer who represented local Aboriginal interests, academic social work staff, and technical and e-learning experts. With guidance from the project team and drawing from the methodology used by Maynard-Moody and Musheno, (2003), two experienced social workers who were working as child protection social work advisors for the Department of Children and Families, were asked to construct a narrative of their most difficult case scenario "with a beginning, and middle and an end", telling the story about "a difficult decision they had to make in the course of their professional work". These narratives were then scripted with key characters and enacted with actors, and filmed. To provide the framework to approaching the design and filming of the case studies, an earlier experience of producing e-learning resources was referred to. The second author had produced a series of podcasts on the use of clinical supervision in 2008 whilst co-ordinating a postgraduate allied health programme. The resource produced in 2008 was a series of four case studies depicting a student social worker taking key ethical dilemmas to clinical and cultural safety supervision to deliberate upon alternative lines of action and recording her feelings about the case in question. The feedback from teaching with the resource from the postgraduate students in 2008 was that it made the process of clinical supervision more transparent and inspired students to use their own clinical supervision more confidently and proactively (Pack, 2009a, 2009b, 2009c, 2011a, 2011b). These earlier-produced e-learning resources provided important background as to how to approach the current project and provided another, more experiential, knowledge source to drawn upon.

The stories were recorded by video and their transcripts then formed the basis of a scenario-based learning programme developed through the software Articulate Storyline (Articulate Global, 2017). These scenarios were embedded in trial format, in appropriate units within the Bachelor of Social Work such as the unit dealing with ethical decision making. Flow charts from local child protection services showing what to do when child abuse was discovered by the social worker's assessment or in a direct report, was embedded in various scenarios. These flow charts used by the departmental child protection social workers were embedded alongside the podcasts of an actor who played the social worker in each filmed scenario (Pack, 2016). Once the case was deliberated on by the social worker during extended monologues, the departmental manual with the decision-making flow 
charts were referred to. In child protection contexts in the Northern Territory, social workers use these decision-making trees as assessment tools to guide some of the critical practice decisions in their work such as what behaviours constitute abuse and when to make a formal child abuse notification.

The case studies were embedded in an Open Education Resource (OER) so that once completed they could be made accessible for social work educators worldwide to access and use the resource on a creative commons website. The case studies were recorded in their entirety with some narratives and alternative stories edited and parts added later after consultation and with the project team. The grandmother's story in one of the scenarios is an example of a late inclusion to share perspectives of extended family responses to the events of a children's disclosure of abuse. These later additions were made to offer an alternate narrative for students to consider.

\section{Ethical issues}

Participation in the teaching and learning project was advertised among social work staff within the Department of Children and Families as a voluntary undertaking. This project was framed by a memorandum of understanding between the university and the Department of Children and Families that had been agreed to in 2012. Two experienced child protection social workers had indicated by return email that they wished to participate. A fact sheet about the project and a consent process advised that interview transcripts would be developed in a way that would take care to avoid identifying the workers or the clients in the case scenarios. The participants were advised that their transcripts were to be kept securely and that their contributions could be withdrawn at any time if wished. Debriefing and counselling services were offered if the interviews evoked any difficult feelings or unresolved issues. Both social workers did not mind being personally identified as they had taught within professional social work courses previously and understood the purpose of the case study project as a workforce development initiative. With the memorandum of understanding forming an overarching relationship between the two institutions, our aim as a team was to work collaboratively in the interests of workforce development. Therefore, an agreement was made that the development of the case studies would be developed collaboratively with the project team and that every effort would be made not to identify any clients, past or present.

The memorandum of understanding between the university and the Department of Children and Families was referred to when ethical issues arose so that the parties could resolve any issues collaboratively. There was one problem with ensuring anonymity of the material. One of the two social workers voiced concern about disclosing details which were felt to be potentially identifying of a high-profile media case. The project team decided to assemble composite case studies involving some changes of detail such as geographic location, ages and gender thus avoiding association with actual child protection cases with high local media interest. This step, and team involvement in what was left in and out of the case studies also avoided potential bias by ensuring that the researcher was not the only person analysing and evaluating the interviews for assembling into case studies.

A trained actor working for the local theatre company was employed to play the part of the social worker. Together with technical staff from within the university who were providing technical expertise in the production phase, the four embarked on producing the resource. The second author scripted and directed the video production based on her experience of having previously produced a resource in the Aotearoa New Zealand context (Pack, 2009b, 2009c, 2011a, 2011b). There were occasions when the actor wanted to interpret the script his way and the first author collaborated with him on each occasion to come to an agreement on ways forward. 
The need to ensure the material used in the filmed scenarios was accurate from a child protection social worker's perspective was the paramount consideration. This was because students were asked to apply the actual departmental decision-making hierarchies and guides to contextualise the experienced practitioners' narratives. The intention was to evoke the use of intuition, judgement, embodied ethics and the exercise of discretion in the context of child protection services. The dimensions of culture, age and gender were also addressed in each scenario to provide authenticity in relation to the complexity of the social workers' decision making with clients (Pack, 2016).

\section{Results}

The filmed scenarios were produced and then edited for technical quality by the camera and filming assistant in the studio. The project team then viewed the webbased material once this rough editing was completed. The project team asked for a multi-disciplinary team scene to involve the doctor and nurse who were caring for the children during an in-patient admission. The simulated hospital ward was used as the Nursing Faculty used this for teaching purposes. Once edited, the resource was then embedded into a web-based application using the e-learning platform, Blackboard version 9. The use of material was agreed for release by each participant. The completed resource is now being evaluated from the student and educator perspectives more formally and is available for other educators to view.

The next section documents how the case studies were integrated to renovate the existing bachelor of social work curriculum. The overall design of the case studies depicting authentic scenarios in social work in child protection moved from a less complex scenario to a case highlighting the most complexity. The case studies evoked moral reasoning and conflicting feelings as each illustrated different scenarios in child protection practice. The first scenario involved assessment of malnutrition of twins living in a remote Aboriginal community; the second dealt with the neglect and abandonment of a 16-year-old by foster carers; and the third described the medical discovery of a sexually transmitted infection in a child living with extended family in a rural location. Each scenario was based on a composite of cases the child protection social work advisors in the project team had worked on. In each case, the social worker's relationship with colleagues and the team as well as the organisation setting were highlighted.

The short film segments were reviewed and consideration was given to what potential areas of learning the case studies would explore. The guidelines for authenticity of case studies were drawn on. These criteria for authenticity were that the case studies:

- add context to theory

- make theory more "real" for students

- encourage student thinking and response to practice dilemmas

- evoke critical reflection on practice and the application of knowledge

- encourage students to see and imagine possibilities

- order experience that helps to bridge the gap between personal situated knowledge and generalizable, sharable knowledge

(Schulman, cited in Darling-Hammond and Synder, 2000, p. 530).

Most of the filmed case material was to be embedded in a third-year ethical decision making in social work unit and re-iterated in a legal issues in social work unit, which is in the final year of the degree. This focus on the third- and fourth-year units was based on the assumption that students had experienced the realities of practice in their first field work placement and engaged in their second, and so would be able to better understand the social worker's deliberations and critical reflective process. 
While viewing the film segments, notes were jotted down as themes relating to social work practice in child protection began to emerge from the story. Alongside these themes a range of strategic questions were developed to prompt students to explore and discuss the dilemmas experienced by the child protection worker. In making decisions about what to embed and how to embed the film segments into the resource, we drew on our previous practice and teaching experiences. The resource embodied many of the unwritten and unspoken dilemmas experienced by child protection social workers captured in facilitated conversations in learning environments. There was a reliance upon local practitioners and colleagues as there was a level of awareness about the inexperience of child protection workers in a Northern Territory context.

\section{Decolonising our practices as social workers}

The recognition of indigenous knowledge is also an important consideration given that the stories embedded within one case study focus on an Aboriginal family from a remote community in the Northern Territory. Working as a social worker in the Territory requires a "can-do" attitude when resources are often lacking and harsh climatic conditions provide challenges such as flooding and life-threatening cyclones or, conversely, arid, desert conditions. Therefore a need to adopt a pragmatic and strengthsbased approach to the challenges of the job as a social worker is a pre-requisite in the job description. For example, social workers are often given rudimentary training in mechanics in case their departmental cars break down in remote areas as they often are too far from an emergency breakdown service or garage. Water and supplies need to be carried in case of getting lost or braking down in remote areas. Under-resourced communities can be stereotyped as lacking amenities and as having more social problems than others which sometimes negates a strengths-based approach to the work. Similarly, there is a dilemma in being part of the development of a resource that presents a case study in a "problemsaturated" way. However, the narrator of the story framed the story of her practice in this way and we wished to remain true to her storytelling. The story embeds the dominant discourse about Aboriginal families depicting imagery of disadvantage, dysfunction and chronic neglect. The approach that was employed to examine this dilemma was one that embedded consultation to gain feedback from key Aboriginal staff working in child protection with whom we were able to openly discuss concerns and make amendments to the resource-including the removal of some content. This process involved deep listening (Bennett, Zubrzycki, \& Bacon, 2011) and reflection about the issues that were being discussed and raised in relation to addressing cultural stereotyping while preserving the educative value of a resource. For example, alcoholism in remote Aboriginal communities is often depicted as being "the problem" to be addressed by social workers when there are local elders in Aboriginal communities who are actively tackling the issue themselves through cultural re-moralisation and strengthening family and community ties at the grassroots level (Bennett et al., 2011). Accordingly, the role of Aboriginal community workers and community elders as advisors working alongside social workers was an important feature of the filmed resource.

The case studies are intended to create a window into the realities of practice and aim to expose students to the reflections of a new graduate, white social worker and his feelings of uncertainty and ignorance about working with Aboriginal people. This reflects the realities of practice for many contexts social workers are employed in and it is important to have the spaces within social work education to build opportunities, case studies and resources that guide learners towards best practice approaches and discussion around cultural safety and competence. These resources provide a safe starting place for exploration of culture and 
social work practice including an analysis of power through decolonising social work and child protection policy and practices.

\section{Embedding the resource in the curriculum}

This stage of the project involved reflecting on the entire social work curriculum and where the resource, or elements of the resource, could be embedded. Whilst the resource was being developed, the social work programme was in the process of going through reaccreditation. This process allowed us to have a holistic perspective of the social work programme rather than being compartmentalised into academic specialities. The original intention was to share the resource with other educators, therefore, having the potential to be a stand-alone interactive web-based resource. However, alternative views existed based on the definition of what was meant by a web based resource, and that the resource needed to be packaged in such a way that it was directed at social work education staff at a tertiary level and that the resource could be made available to others under the licensing agreements. This is where the idea and development of a resource using a MOOC format on a freely available web platform seemed to make sense.

The content of the case studies themselves could be embedded across a number of the component units in the four-year social work degree. As previously mentioned and originally envisaged, the resource would be integrated with third- and fourth-year units of study such as "Legal issues and social work"; "Social work theory and practice"; and "Ethical dilemmas in social work". Later it was considered that some of the units offered to an interdisciplinary degree, for example with health science, midwifery, humanitarian studies and behavioural science students, may also be able to make use of the resource due to the interdisciplinary nature of child protection work. Social work educators are free to adapt the resource as it fits into their specific teaching approaches and course structures.

\section{Partnership principles and collaboration}

The development of this resource was a collaborative effort involving partnership between social work practitioners, local child protection services, the local community and the university. The layers of collaboration began as the relationship among the project team commenced and grew. Involvement came from different individuals at different phases of the project. These relationships began with formulating the grant application and continued with researching practitioner stories and experiences, collaboration amongst academic staff from the areas of teaching and learning and social work. The inclusion of Aboriginal colleagues' perspectives and close work with the technical experts deepened these relationships. Whilst there were many barriers to collaboration, in particular in relation to the sensitivity of the content, close working relationships between the social work academic and practice staff and the media production team were formed and continued to be integral in producing the actual resource.

The resource included stories of children and families who are vulnerable. In particular, the construction of Aboriginal people by the resource gained the most attention during the discussion. To avoid identifiability and for ethical reasons, all the practitioners' personal details were changed in the scenarios that were recorded. The monologue of the social worker in each scenario deliberating on what to do within each of the case studies involved such themes as transference between client and worker, and involved aspects of his own biography that were fictional. Students viewed this resource and were engaged through a series of reflective questions to ponder on their own responses to the case including what they thought the social worker would do. In one scenario, the social worker had a personal issue triggered by working with a client facing a similar issue. The decision to explore a sensitive issue 
of a social worker's personal life being evoked by working on a case involving abuse and neglect was a highly controversial one. The technical staff of the project team thought this scenario seemed implausible and unusual, and wanted to edit out this monologue. The practitioners who had provided their narratives thought it was an accurate depiction of what very often happens for social workers in dealing with clients who have traumatic and abusive histories. The vicarious traumatisation, secondary traumatic stress, traumatic transference and self-care literature is an important evidence-base for students to be aware of before they embark on their careers as social workers.

\section{Teaching with the resource}

To informally gauge how useful the resource was for students, the first author used it in her pre-placement intensive workshop which ran for five days. This face-to-face workshop is designed to prepare students for some of the situations and theories that can inform practice before they embark on their first practicum placement. The feedback from students was informative as to how far the project had met the original objective of being authentic in the sense of realistically depicting the context for practice. By engaging students' imagination, critical reflection and the application of theory to practice through moral and ethical reasoning, the criteria for authenticity of case studies, the resource seemed to be meeting the brief set for it.

We also wished to model the cultural and organisational contexts in which social workers daily navigate a moral and ethical minefield mirroring Lipsky (2010) and Maynard-Moody and Musheno's (2003) work on street-level bureaucracy and the use of discretion in the human services. The feedback from students was that the monologues from the actor as the social worker were the most valued parts as he reflected aloud in the moment on "on-thejob" dilemmas evoking personal responses and emotions. Specifically, the students enjoyed hearing the social worker discuss his feelings of being out of his depth, as a young, white Australian man working with Aboriginal families living remotely in the community. This is a critical theme to be explored in all social work education to align with the principles of partnership inherent in the Treaty of Waitangi in Aotearoa New Zealand and to align with the professional codes of ethics of the AASW and the ANZASW. The students said that they valued exploration of working across cultures reflectively as there can be many emotional issues to be acknowledged and worked through in coming to an awareness of one's own cultural identity. Discussions of history, power and privilege are central considerations evoked in such classroom discussions, linking to decolonising practices (Smith, 1999).

Secondly, the case study dealing with the social worker grappling with personal issues in his own past which were evoked by the process of working on a case, was highly valued by students. This prompted learning about what to do if similar issues arise upon working in one's placement and ideas for self-care plans on practicum were discussed in class. Emphasising the importance of seeking both clinical supervision and counselling to address the inevitable issues of the professional triggering the personal is an integral part of pre-placement preparation. It is noteworthy that students disagreed with the filmed scenario of triggered issues being raised in clinical supervision. Due to more managerial models of supervision being the norm in statutory practice, student counselling was considered more appropriate by the students as a first port of call in dealing with transferential responses and past trauma. The potential for vicarious traumatisation of workers is strongly recommended in the literature on preparing workers for on-the-job challenges when working with trauma (Furlonger \& Taylor, 2013). This includes reference to the importance of relational modes of clinical supervision for beginning practitioners and 
those dealing with trauma (Baum, 2007; Bogo \& McKnight, 2005; Pack, 2014). Our experience of these classroom discussions, facilitated by the use of our filmed resource, affirms the place of teaching about self-care and self-awareness.

Similar themes resonated with social work academics when early drafts of the edited videos were presented at an international social work conference by the second author. Educators from the United Kingdom and Canada remarked on the power of scenes were the social worker took time out to reflect on what to do next. The depiction of these monologues happening in the tea room, his office, in team meetings; with clients and their families, and on the telephone to colleagues was valued for being naturalistic and true to the day-to-day world of practice where social workers are required to think on their feet and act in the moment. This "thinking on our feet" theme appears easy to do but is a complex process involving the practitioner pausing to reflect, critically reflecting alone or with others, and then acting in cycles of action-reflection described by educational theorists such as Schön (1987). This kind of exploration of how to reach lines of action out of complexity and ambiguity, involving difficult decisions can be descriptively described, but less tangibly depicted, in text-based resources.

To date, there have been in excess of 460 online hits from educators viewing our resource on the blackboard course site established to showcase the teaching resource. The plan following formal evaluation of the resource and how it is used in teaching is to have the resource available on a creative commons website for all educators to draw from and adapt the material to their cultural and multidisciplinary contexts of practice.

\section{Conclusion}

We have developed three questions now that the project is about to undergo more formal evaluation: firstly, what are our responsibilities as educators in the construction of case studies? Secondly, how do we ensure these case studies are authentic and therefore stimulate active learning? Thirdly, why is there often resistance to these stories being available as educational resources? These issues are on the agenda to be evaluated by a researcher who was not a part of the design and delivery of the resource.

What seems clear to our team in completing the project with the research, production and use of the resource is that social work and social workers need to be prepared to decolonise our own practice through a critical-reflective process focusing on an analysis of the use of power. Because of the imposition of cultural norms by the predominant culture, it is important to consult with client groups and communities about their priorities; these need to be included in the design of case studies. This theme became apparent when a scene involving a fridge/cupboard inspection as part of a child neglect investigation was embedded in the script aligning with one of the social worker's narratives of practice. Our child protection social workers advised the project team that is a common practice in investigating child welfare in remote communities were child malnourishment is assessed. There was criticism later from another departmental advisor that this practice was no longer commonplace and in fact, was not recommended, yet the narrator challenged that assumption. In her experience, this was a customary practice to determine if there was enough food available to the family so that the need for financial assistance/food vouchers could be accurately assessed.

In this debate between policy makers and practitioners, we hear Lipsky's (2010) streetlevel practitioner's use of discretion echo and come to life, through an example of the individual practitioner drawing from a personal sense of ethics that involves one's own attitudes and prejudices that exist in a dynamic tension alongside 
official policy and practices. Secondly, the institutional racism of viewing Aboriginal clients in remote communities as living in financial deprivation/need when this may more accurately reflect a white Australian perception based on cultural misunderstanding and misinterpretation of lifestyle preferences, is also highlighted by this case scenario. As one of our child protection social workers remarked, some Aboriginal communities shop to satisfy the white, middle-class, affluent, expectations of the social worker for there to be food in the cupboard when a departmental visit is planned to the community. Specifically, a trip to the local store for an acceptable store cupboard staple such as Weetabix, was a common response of residents of remote Aboriginal communities to news of a social worker's impending visit. Such sub-narratives are also important to include.

Despite controversy about the use of case studies in social work education, there remains a strong interest for human service professionals to be engaged in learning in the area of discretion in a range of contexts including higher education, vocational education and in the workplace. The resource we have produced examines child protection from the social work case management point of view. However, there is scope to examine such case studies from different angles. For example: a narrative reflecting a paediatric nurse, a doctor or a community worker. There is also potential scope to include narratives from the client perspective including a critique of social work and the institutional racism that exists despite best efforts to the contrary.

This article has identified significant potential benefits in incorporating online and digital resources in learning for developing social work students' capacity for decision making in complex scenarios. Ultimately, the curriculum design scaffolds through actual demonstration from theory to practice to prepare students for dealing with child protection social work.
Resource URL: https:/ /www.coursesites. com/webapps/Bb-sites-course-creationBBLEARN/courseHomepage.htmlx?course_ id=_343081_1

\section{References}

Articulate Global. (2017). Retrieved from https://www.articulate. $\mathrm{com} / \mathrm{lp} /$ create-elearning-courses-with-storyline/?utm source =google\&utm_medium=paid-search\&utm content=branded\&utm_campaign=storyline \&gclid=COOL 1amrmMUCFYiCvQod7AEAbA

Baum, N. (2007). Field supervisors' feelings and concerns at the termination of the supervisory relationship. British Journal of Social Work, 37, 1095-1112. doi:10.1093/ bjsw/bcl057

Bennett, B., Zubrzycki, J., \& Bacon, V. (2011). What do we know? The experiences of social workers working alongside Aboriginal people. Australian Social Work, 64(1), 20-37.

Bloomfield, D., Chambers, B., Egan, S., Goulding, J., Reimann, P., Waugh, F., \& White, S. (2013). Authentic assessment in practice settings: A participatory design approach. Sydney, NSW: Office for Learning and Teaching.

Bogo, M., \& McKnight, K. (2005). Clinical supervision in social work. The Clinical Supervisor, 24, 49-67. doi:10.1300/J001v24n01_04

Coursesites by Blackboard. (n.d.). Retrieved from https:// www.coursesites.com/webapps/Bb-sites-coursecreation-BBLEARN/pages/index.html

Darling-Hammond, L., \& Snyder, J. (2000). Authentic assessment of teaching in context. Teaching and Teacher Education, 16, 523-545.

Furlonger, B., \& Taylor, W. (2013). Supervision and the management of vicarious traumatisation among Australian telephone counsellors. Australian Journal of Guidance and Counselling, 23, 82-94. doi:10.1017/jgc2013.3

Gambrill, E. (2006). Critical thinking in clinical practice: Improving the quality of judgments and decisions. Hoboken, NJ: John Wiley \& Sons.

Lipsky, M (2010). Street level bureaucracy: Dilemmas of the individual in public services. New York, NY: Russell Sage.

MacDonald, J. (2002). Clinical supervision: A review of underlying concepts and developments. Australian and New Zealand Journal of Psychiatry, 36, 92-98. doi:10.1046/j.1440-1614.2002.00974.x

Maynard-Moody, S., \& Musheno, M. C. (2003). Cops, teachers, counselors: Stories from the front lines of public service. Ann Arbor, MI: University of Michigan Press.

Maynard-Moody, S., \& Musheno, M. (2012) Social equities and inequities in practice: Street-level workers as agents and pragmatists. Public Administration Review, 72(1), 16-23. doi:10.1111/j.1540-6210.2012.02633.x

Mezirow, J. (1990). How critical reflection triggers transformative learning. In J. Mezirow (Ed.), Fostering critical reflection in adulthood: $A$ guide to transformative and emancipatory learning (pp. 1-20). San Francisco, CA: Jossey-Bass Publishers.

Napier, L., \& Fook, J. (2000). Breakthroughs in practice: Theorising critical moments in social work. London, UK: Whiting \& Birch. 
Pack, M. J. (2009a). Clinical supervision: An interdisciplinary review with implications for social work. Reflective Practice: International and Multidisciplinary Perspectives, 10, 657-668. doi:10.1080/14623940903290729

Pack, M. J. (2009b). Supervision as a liminal space: Towards a dialogic relationship, Gestalt Australia and New Zealand, 5(2), 60-78.

Pack, M. J. (2009c). Allies in learning: Critical-reflective practice on-line with allied mental health practitioners. Social Work Education: The International Journal. 29, 67-79. doi:10.1080/02615470902810876

Pack, M. J. (2011a). The design and development of teaching resources for the purpose of demonstrating aspects of clinical supervision: Developing the on-line community of learners. Advances in Social Work Journal, 13, 111-126.

Pack, M. J. (2011b). Making the unseen seen through the use of multimedia approaches in counselling and social work education. Junctures: The Journal for Thematic Dialogue, 13, 69-75.

Pack, M. J. (2014). Unsticking the stuckness: A qualitative study of the clinical supervisory needs of early career health social workers. The British Journal of Social Work, 45(6), 1821-1836.

Pack, M. J. (2016). Learning to "think on our feet": Producing a new digital resource for teaching social work students about reflective decision-making in child protection practice in Australia. Practice: Social Work in Action Journal, 28(3), 213-226. doi:10.1080/09503153.2015.1087490

Ryan, M. (2013). The pedagogical balancing act: Teaching reflection in higher education. Teaching in Higher Education, 18(2), 144-155. doi:10.1080/13562517. 2012.694104

Schön, D. (1987). Educating the reflective practitioner: Toward a new design for teaching and learning in the professions. San Francisco, CA: Jossey-Bass.

Smith, L. T. (1999). Decolonizing methodologies: Research and indigenous peoples. London, UK: Zed Books. 